\title{
CONCEPTUAL FOUNDATIONS FOR A NEW LEAN BIM-BASED PRODUCTION SYSTEM IN CONSTRUCTION
}

\author{
Christoph Paul Schimanski ${ }^{12}$, Gabriele Pasetti Monizza ${ }^{2}$, Carmen Marcher ${ }^{12}$ and \\ Dominik T. Matt ${ }^{34}$
}

\begin{abstract}
This paper presents a new lean BIM-based production system to face productivity deficiencies in construction. To prove whether the current situation can be improved, the aforesaid production system is designed to assess the hypothesis that a true integration of BIM functionalities with the Last Planner System will contribute to a more efficient project delivery. Although beneficial synergies of BIM and Lean have been widely described and acknowledged in research, previous work has not fully addressed the stated hypothesis, since it has only provided frameworks on how to use BIM and the Last Planner System in parallel. The core of the here-proposed lean BIM-based production system is the linkage of BIM objects at data processing level with the Last Planner System routines making use of digital Kanban boards. The production system will also be extended by cost control aspects of the Earned Value Management approach and thus represents the basis for a complete construction management system with respect to quality, schedule and costs. This paper discusses the first concepts of the new lean BIM-based production system and introduces an information system integration model as a starting point for future software development activities.
\end{abstract}

\section{KEYWORDS}

Production System Design, Industry 4.0, Lean and BIM, Last Planner System, Digital Kanban

\section{INTRODUCTION}

The digitization, which is often referred to as Industry 4.0 in industrial production, is seen as one of the keys to increase productivity in construction (Dallesega et al. 2015). Building Information Modeling (BIM), as a method for digital representation of physical and functional characteristics of buildings and the data provided in this way, can be considered as the starting point for Industry 4.0 in construction. While Industry 4.0 in stationary

PhD Cand., Faculty of Science and Technology, Free University of Bozen-Bolzano, Italy,

christophpaul.schimanski@natec.unibz.it

Research Associate, Fraunhofer Italia Research, Bolzano, Italy, christoph.schimanski@ fraunhofer.it

Head of Fraunhofer Italia, Fraunhofer Italia Research, Bolzano, Italy

Full Professor, Faculty of Science and Technology, Free University of Bozen-Bolzano, Bolzano, Italy 
manufacturing aims at reaching the highest possible flexibility whilst maintaining productivity rates of the mass production era, the construction sector wants to industrialize the de facto existing one-of-a-kind production and thereby increase productivity (Pasetti Monizza et al. 2018).

To this end, the challenge of making BIM data systematically available for the execution process needs to be addressed. One possibility for the standardization and systematic use of BIM models in execution is seen in the combined use with Lean Construction methods (LCM) (Sacks et al. 2010a). In fact, synergies resulting from BIM functionalities and Lean principles are described in numerous scientific publications (Dave et al. 2013; Khan and Tzortzopoulos 2014; Sacks et al. 2010b; a). More in detail, the Last Planner System (LPS) was identified as the most suitable lean method for construction execution processes to exploit these synergies (Sacks et al. 2010a). The LPS developed by Ballard (2000a) supports production planning and control by providing systematic routines to increase workflow reliability and process stability. The most important pillars for achieving that are collaboration, transparency, continuous improvement and commitment from task leaders responsible to actually fulfil the work on site, the Last Planners. However, Uusitalo et al. (2018) bewail that the LPS does not offer indications for its application in BIM-based processes.

Nonetheless, several attempts have been made to combine LPS and BIM in practice and scientific contexts. This paper briefly describes these attempts and will discuss their limitations of constituting solely frameworks for co-application, rather than true integrations. Given that, we propose an integration model on data processing level which lays the foundation for a new BIM-based production system, making use of the Industry Foundation Classes (IFC) as a non-proprietary data exchange format for BIM models. For convenience wording and as a symbol for the fusion of BiM and Lean, we will name this production system: BeaM!

\section{RESEARCH METHODOLOGY}

This paper follows a combined research approach which is composed of systematic literature review addressing the co-applications of BIM and LPS in previous studies and a Design Science Research (DSR) approach to develop new artefacts for system integration of BIM and LPS allowing for a joint application. The starting point of the DSR approach is a specific problem, which is followed by elaborating hypotheses for a possible solution of that problem based on previous knowledge and the literature review. Subsequently, in the development phase we will create concrete artefacts, in this case the BIM-LPS integration model and a description of the new process. The evaluation foreseen in DSR is not part of this study and will be dealt with in future studies. The development of the integration model itself follows Highsmith (2002) proposal for method development and considers not only the methodology and process perspective but also other environmental impacts, so that a holistic ecosystem is presented embedding $\mathbf{B} e a \mathbf{M}$ ! as a new production system. 


\section{STATE OF THE ART: BIM-LPS CO-APPLICATIONS}

Literature reveals still problems at integrating BIM with LPS. Amongst these, Toledo et al. (2016) criticize that recent LCM and BIM research is limited to theoretical synergy possibilities of both approaches and that little focus is placed on the development of practically applicable methods and tools. Therefore, they propose a Lean-BIM planning framework, in which they include an Autodesk Revit ${ }^{\circledR}$ BIM model in the LPS process and explain how it can be used most efficiently in the various LPS phases.

With the Smart Construction Planner, Guerriero et al. (2017) developed a Lean IT-tool which supports for collaborative planning according to the LPS. Additionally, they mapped the LPS steps to BIM 4D scheduling and argue that a framework for joint application should follow their research activities.

Gerber et al. (2010) investigate the co-application of selected BIM functionalities with certain Lean principles from Sacks et al. (2010a) in case studies. One of these case studies interprets BIM as a starting point for process planning and lookahead planning, not considering the LPS methodologically to its full extent though. However, in their opinion, both approaches Lean and BIM are inextricably linked, but further research would be needed to support their hypothesis.

Bhatla and Leite (2012) also attempt to combine LPS and BIM application for evaluating the hypothesis that LCM and BIM are not independent of each other and most benefits can only be obtained when both approaches are used together. However, they implemented only look-ahead and weekly work planning (WWP) of LPS which were included in regular BIM coordination meetings. In addition to only partial LPS implementation, it can be criticized that the make-ready activities were limited to clashfree MEP ducts which were checked by using BIM models.

Garrido et al. (2015) use an integration framework of BIM and LPS developed by Mendes Júnior et al. (2014) in two case studies in Brazil. They conclude that BIM models support decision making processes during LPS phases due to their ability to provide right information at the right time. However, in these contributions, BIM and LPS are not used in an integrated information system, but one system supports the other in a detached way.

Moreover, Lagos et al. (2017) emphasize that the IT-supported use of LPS correlates positively with Percent Planned Complete (PPC) values. In their opinion, especially during the planning of the execution process, the systematic make-ready process of tasks as well as progress monitoring can benefit from IT-support. However, the authors claim that standardization in this sense can only be achieved by improved communication and a frame-giving Knowledge Management System (KMS). BIM can be interpreted as an approach for an effective KMS (Deshpande et al. 2014), which is taken up by Hasan and Akbas (2017) by claiming that BIM has the power to improve and streamline look-ahead planning. Nonetheless they see big challenges in structuring data and making it available for managing the execution process on site. Addressing this challenge, they propose a generic information management approach by aggregating the BIM data and other information required for look-ahead planning such as crews, equipment and basic workflows on an online platform. This platform is a prototype simulation platform which automatically generates a simulation model for construction processes for a given input. However, the collaboration aspect of the cooperative phase planning of the LPS is 
neglected and the focus is placed on computer-assisted optimization of master schedules rather than establishing a production system according to Lean thinking.

In the field of BIM and Lean supporting IT systems, VisiLean, developed by Dave et al. $(2013,2011)$, has to be mentioned. It is a cloud-based construction management tool that supports LPS principles and pairing with BIM. Tasks can be linked directly to BIM objects and thus the progress can be visualized by means of the model. However, for these tasks, quantities and other BIM information must be entered manually. The BIM model does not deliver them automatically. Furthermore, within the system a phase is solely interpreted as a far-reaching look-ahead window (e.g. 3 months). Nevertheless, elements such as deep collaboration and hand-offs discussion amongst the Last Planners, characterizing the cooperative phase planning, are not considered.

In addition, and with regard to information systems, Sacks et al. (2010c) describe a list of six requirements as decisive for an integral BIM-based lean production management system for construction, most of which relate to visualization capabilities, the establishment of pull systems, workflow stability and continuous improvement. These requirements have been implemented in the IT system KanBIM (Sacks et al. 2010b; c) which is based on the hypothesis that IT systems can significantly enrich the LPS by enabling access to 3D building representations. Being a non-BIM approach, in our opinion, pure geometric 3D representations are not sufficient for a complete construction production system with regard to the three target variables quality, schedule and costs. We consider it as extremely important for an effective production system to have an exact knowledge of the quantities to be built on and the associated costs in order to be able to pursue the road towards industrialised construction processes. Therefore, we propose the addition of point (7) Automatic and precise quantity-take off for process management to the list of Sacks et al. (2010c) requirements. To further complete this list, we also suggest introducing (8) Clear roles within the processes. The latter point is taken up again and explained in the design of the new lean BIM-based productions system described below. We take these requirements and the described current absence of a linking of BIM and LPS to a new information system as an opportunity to propose a concept for a new lean BIM-based production system in construction.

\section{THE NEW PRODUCTION SYSTEM}

Production goals in construction usually direct to the optimization of the interrelated target variables quality, schedule and costs (Borrmann et al. 2018), for which planning reliability and process stability in execution plays a crucial role (Kim and Ballard 2010). Consequently, methods directed to these objectives, such as for example the LPS, become anchors for production systems in construction (Hamzeh et al. 2012).

\section{Design of The New Production System}

Hence, assuming the LPS as foundation for our new production system and being set to truly integrate it with BIM, the design of the BeaM! system technically represents a system integration on data processing level of the two sub-systems BIM and LPS to deliver new functionalities and exploit synergies. Eventually, both sub-systems should work together, where their conjunction will be expressed through an integration model. Regarding new 
functionalities and in addition to already mentioned individual BIM and LPS strengths, we have identified three major aspects for potential improvement, which consequently will be added into the integration model. These three aspects are (1) elements of the Scrum method, as a representative for agile project management (APM) techniques, the (2) implementation of a digital Kanban board to make use of both the Kanban method itself and enhanced visualization capabilities of digital whiteboards and (3) adding features of the Earned Value Management (EVM) project control system since LPS lacks in controlling cost performance (Novinsky et al. 2018).

Adding aspects of Scrum: After investigating the applicability of agile project management ideas in construction execution, Owen and Koskela (2006) suggest beneficial applications in process planning of execution but not for the site-management itself. Contradictorily Fernandes and Ribeiro (2010) state that agile techniques were suitable for steering all project phases in the context of medium and small sized enterprises (SMEs). Based on these prospects, we want to discover the potential of APM aspects for the BeaM! system. Particularly, we see value in adopting Scrum's clearly defined roles to our proposal. Since literature showed that main barriers of successful LPS implementation amongst others are comprised of poor methodological correctness and partial implementation, we think that precisely formulated roles with distinct responsibilities in the single process steps will improve the production system. Whilst LPS routines of iteratively checking commitments and learning cycles intrinsically cover some agile ideas already, we want to extend the BeaM! system by introducing new roles analogously to the Scrum framework. For establishing a parallelism to the game of chess, we call these roles the BeaM!-King and the BeaM!-Knight, which will be described in detail later on.

Adding aspects of (Digital) Kanban: A Kanban system provides information in terms of pull signals along value-adding-chains in manufacturing settings by means of cards or boards. Applied to the LPS, it can support the pull planning requisite of task-completion releasing new work (Ballard 2000b). Thanks to the information provided by the Kanban, task specifications and sequencing are clearly visible to workers or respectively to Last Planners (Matt and Rauch 2014). In addition, Mossman (2015) emphasizes the success factor of visualization when implementing the LPS. Therefore, today sticky-notes are standard for a visual representation of the LPS. Beyond that, Modrich and Cousins (2017) hypothesize that the joint use of LPS with Kanban techniques in design is better suited than conventional project management approaches. Based on their study, they conclude that the interaction of LPS metrics and Kanban-board metrics leads to better information flow. We take up this hypothesis and extend it to the execution phase by making our system applicable on digital whiteboards (BeaM!-Board) and enabling Kanban control.

Adding aspects of Earned Value Management: Cost control will be addressed by introducing EVM elements to the BeaM! system. More in detail, BeaM! will compare the EVM metrics Planned Value (PV) which represents the budgeted cost of work scheduled (BCWS) and the Earned Value (EV) which corresponds to the budgeted cost of work performed (BCWP). For applying earned value analysis in $\mathbf{B} e a \mathbf{M}$ !, the LPS will define the work that needs to be accomplished and at the same time determine the "earning-rules" for deciding whether work has been actually accomplished or not. Finally, monitoring the actual costs $(\mathrm{AC})$ and comparing it to $\mathrm{EV}$ will provide for insights regarding overall cost 
status. Here it is important to remark that in any case, the site-management remains governed by a "managing by means" (MBM) thinking approach, which has been defined in Kim and Ballard (2010). This means that cost parameters solely represent informative attributes of LPS operations. However, stabilizing the workflow stays decisive for sequencing these operations.

Complementary applications of LPS and EVM have been recently investigated in Novinsky et al. (2018); Zhang et al. (2018) and disclosed their mutual fit. Since positive findings in Novinsky et al. (2018) were only related to the design phase, we want to extend the joint application also to the execution phase.

\section{Formulation of The New Production System}

The guidelines for designing an agile methodology according to Highsmith (2002) are applied in an adapted form to design the Bea M! system. As Bea M! being embedded in a holistic ecosystem, the latter is characterized by providing not only the new process itself, but defining also emerging roles, scoping the domain of its application and formulating underlying ideals and principles. The comprising parts of this ecosystem are depicted in Table 1.

Table 1: Formulation of the new production system: BeaM!

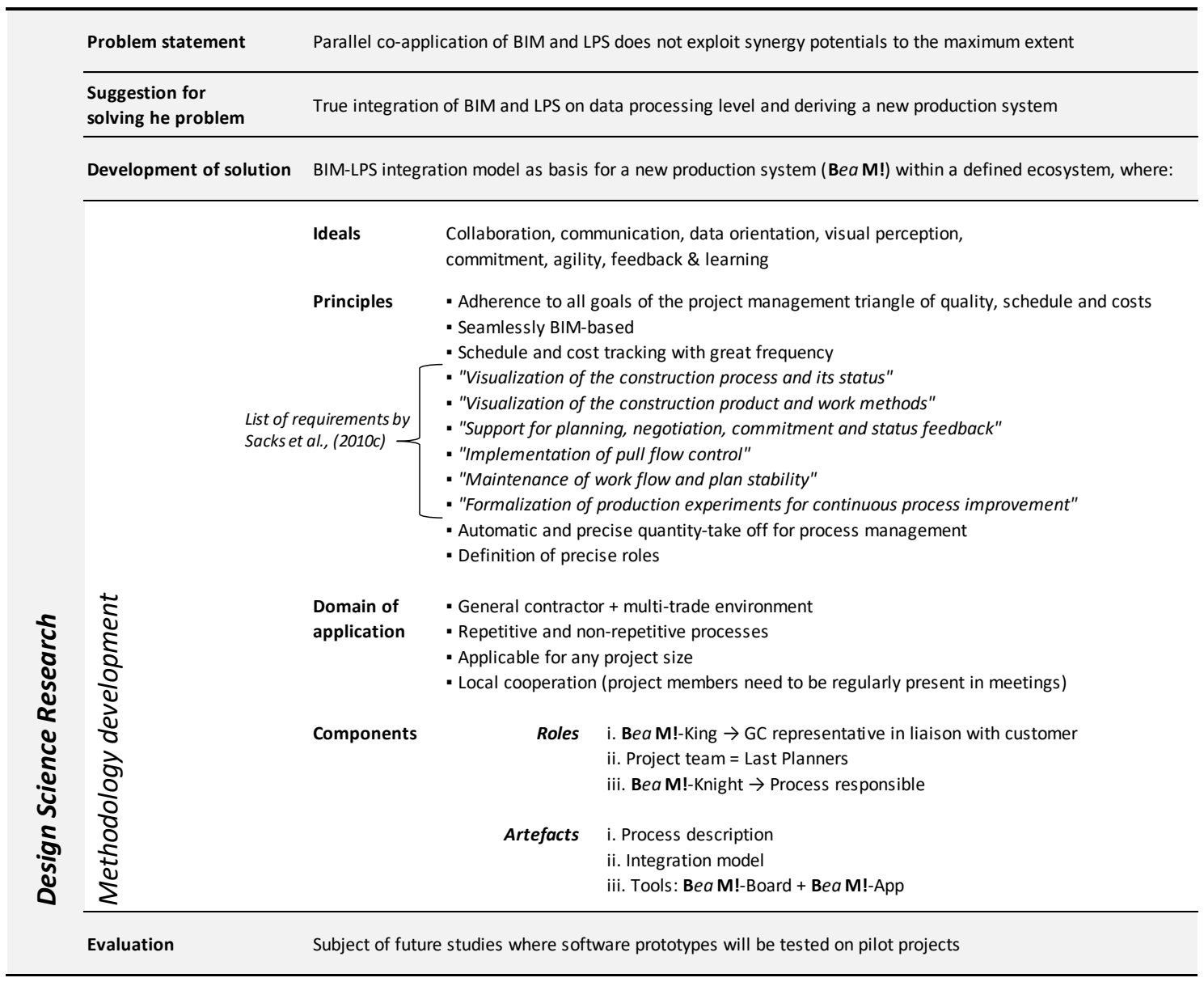




\section{Process DesCription}

In line with the LPS, the starting point for phase planning is a master schedule with milestone representations. The master schedule, together with contractual documents, bills of quantities as well as the coordinated BIM model in the IFC file format, are assumed as given input. Generally, the $\mathbf{B} e a \mathbf{M}$ ! process follows the five-step logic of the LPS but is consistently digitally supported and linked to associated BIM objects except for non-digital master schedules. In addition, the LPS will be methodologically extended in a way, that process-describing sticky-notes - the Digital Process Kanban (DPK) - can be created individually by the Last Planners during phase-planning on their cell phone via the $\mathbf{B} e a \mathbf{M}$ !App. Then, DPK can be literally "beamed" to the BeaM!-Board and will serve as pool for the cooperative phase planning (Figure 1).

Before or during planning the phases, roughly calculated costs will be associated to each DPK which will represent the PV with respect to EVM. Differently to as proposed in Novinsky et al. (2018) and Zhang et al. (2018), underlying quantities do not have to be estimated, but constitute given information as an inherent part of the linked BIM objects.

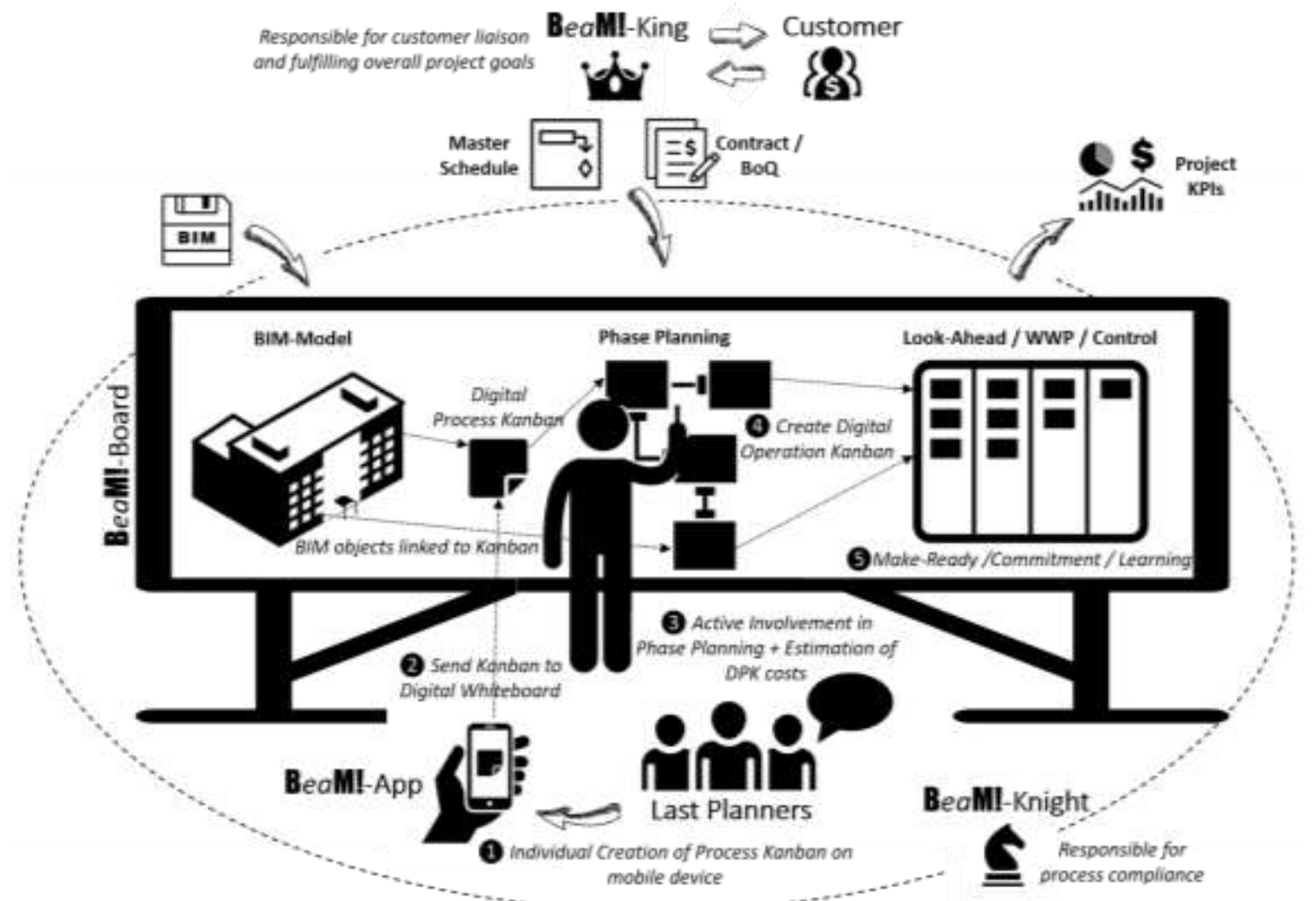

Figure 1: Schematic representation of BeaM!

Nonetheless further DPK can be added anytime to the board when the pull planning process reveals need of other prerequisites or hand-offs. Supposedly, using own cell phones for creating the Kanban will reduce resistance to standing up, labeling and attaching stickynotes to the board. The corresponding BIM objects can be selected in the BIM viewer and 
thereby linked to the DPK. A second possibility is to first select the BIM objects in the viewer via touch control and then to create a linked DPK. In both cases, the BIM-linked DPK are available for phase planning according to LPS, in which the Last Planners are supposed to be actively involved. We experienced in non-digital pull planning sessions that arranging sticky-notes on a board generates significantly less resistance than creating them, so that a lively collaboration can be assumed here, once the DPK are present on the board.

In the next steps which foresee look-ahead and WWP and according to the nomenclature of task granularity provided in Hamzeh et al. (2012), DPK are the starting point to transform processes into assignable operations. These will be represented by new digital sticky-notes, the so-called Digital Operation Kanban (DOK) maintaining the link to the respective BIM objects and quantity information though. An example could be the DPK of producing concrete slab being transformed to multiple DOK such as formwork construction, reinforcement placement and concrete pouring, which still point all to the same BIM objects. In respect of quantities of operations, algorithms can be applied to the DOK for approximative calculations. For example, the quantity in terms of steel tons for the operation of reinforcement placement could be approximated in many cases as an order of magnitude to $10 \%$ of the related concrete volume $\left[\mathrm{m}^{3}\right]$. The definition of such calculation rules is supposed to be subject of discussion amongst Last Planners during make-readyplanning sessions, where their experience from practice will be leveraged purposefully. In terms of costs, Last Planners will have to distribute the PV assigned to DPK to the subordinated DOK on a percentage basis.

Regarding the introduced roles, the $\mathbf{B} e a \mathbf{M}$ !-King is responsible for the creation of phase schedules in accordance with the objectives of the milestone plan and the customer, but has limited action possibilities to intervene in the BeaM!-process itself in line with the established chess parallelism. It is proposed that his role will be filled out by the site manager of the General Contractor (GC). The role of the BeaM!-Knight, on the other hand, can be filled out by either a GC representative or an external project manager. The main task of the BeaM!-Knight is to ensure process compliance and thus also to control the methodological correctness of the individual LPS steps. Analogous to the name-giving chessman, the BeaM!-Knight has the possibility to jump back and forth on the "playing field" and intervene where necessary. Content definition for DPK and DOK does explicitly not fall within his remit. Furthermore, he/she is responsible for moderation and operation of the $\mathbf{B} e a \mathbf{M}$ !-Board during make-ready and commitment planning as well as control sessions and communication of Key Performance Indicators (KPIs). Speaking of LPS's control stage at the end of each week, besides the usual check of commitments and root cause analysis, as an extension of the regular LPS, EV's of each completed DOK will be summed up and used for evaluating the current project performance.

\section{INTEGRATION MODEL}

The integration model is presented according to the steps of the LPS and the link to the BIM model is shown by association on data processing level with respect to the IFC format.

Master schedule: The master schedule with milestone representation is assumed to be a given input. It can be provided in either way, digital or as a not-digital print-out. 
Phase scheduling: In Table 2 phase planning steps 1-6 defined in Ballard (2000b) will be associated to manipulations of an IFC-file as the representative of a BIM model on data level. Besides that, it will be presented how these manipulations are conducted with the BeaM!-Board as a digital whiteboard.

Table 2: Mapping phase planning according to Ballard (2000b) to the IFC data structure

\begin{tabular}{|c|c|c|c|}
\hline Step & Phase scheduling steps $1-6$ by Ballard (2000b) & Digital Kanban-Board functionality & BIM: IFC manipulation \\
\hline 0 & $\begin{array}{l}\text { Have master schedule as starting point and } \\
\text { identify milestones }\end{array}$ & $\begin{array}{l}\text { Select BIM-Objects in IFC Viewer and press } \\
\text { "create Milestone" button }\end{array}$ & $\begin{array}{l}\text { Instantiate IfcTask object and set boolean } \\
\text { IsMilestone to true }\end{array}$ \\
\hline 1 & $\begin{array}{l}\text { "Define the work to be included in the phase; } \\
\text { e.g., foundations, building skin, etc." }\end{array}$ & $\begin{array}{l}\text { Select BIM objects in IFC Viewer and press } \\
\text { "create Digital Process Kanban Button" OR } \\
\text { create corresponding Digital Process Kanban on } \\
\text { mobile device and send it to Bea M!-Board and } \\
\text { then link to BIM objects }\end{array}$ & $\begin{array}{l}\text { Kanban trigger instantiation of IfcTask objects } \\
\text { which are linked to selected BIM objects } \\
\text { (IfcElements) through IfcRelAssignsToProduct } \\
\text { objects }\end{array}$ \\
\hline 2 & $\begin{array}{l}\text { "Determine the completion date for the phase, } \\
\text { plus any major interim releases from prior } \\
\text { phases or to subsequent phases." }\end{array}$ & $\begin{array}{l}\text { Click on respective milestone and set } \\
\text { finish date }\end{array}$ & $\begin{array}{l}\text { Set attribute LateFinish of Type IfcDateTime in } \\
\text { entity IfcTaskTime and relate to milestone } \\
\text { IfcTask objects in step } 0\end{array}$ \\
\hline 3 & $\begin{array}{l}\text { "Using team scheduling and stickies on a wall, } \\
\text { develop the network of activities required to } \\
\text { complete the phase, working backwards from } \\
\text { the completion date, and incorporating any } \\
\text { interim milestones." }\end{array}$ & $\begin{array}{l}\text { Arrangement of Kanban via touch control on } \\
\text { Bea } \mathbf{M ! - B o a r d ~ d e f i n e s ~ d e p e n d e n c i e s ~}\end{array}$ & $\begin{array}{l}\text { Manipulate the IsSuccessorFrom and } \\
\text { IsPredecessorOf attributes of IfcTask objects } \\
\text { defined in step } 1\end{array}$ \\
\hline 4 & $\begin{array}{l}\text { "Apply durations to each activity, with no } \\
\text { contingency or float in the duration estimates" }\end{array}$ & Click on respective Kanban and set duration & $\begin{array}{l}\text { Assign duration through type IfcDuration and } \\
\text { relate to IfcTask objects defined in step } 1\end{array}$ \\
\hline 5 & $\begin{array}{l}\text { "Reexamine logic to try to shorten the } \\
\text { duration." }\end{array}$ & $\begin{array}{l}\text { Collaborative re-arrangement of Kanban via } \\
\text { touch control on Bea } \mathbf{M} \text { !-Board }\end{array}$ & $\begin{array}{l}\text { Update of dependencies in IfcTask objects } \\
\text { defined in step } 1 \text { according to re-arrangement }\end{array}$ \\
\hline 6 & $\begin{array}{l}\text { "Determine the earliest practical start date for } \\
\text { the phase" }\end{array}$ & $\begin{array}{l}\text { Click on first Digital Process Kanban of the } \\
\text { phase and set start date }\end{array}$ & $\begin{array}{l}\text { Set attribute EarlyStart of Type IfcDateTime in } \\
\text { entity IfcTaskTime and relate to first arranged } \\
\text { IfcTask object in step } 5\end{array}$ \\
\hline
\end{tabular}

Make-ready planning (Look-ahead-plan): The make-ready process of moving processes into the look-ahead-schedule, which comprises six weeks, is characterized by identifying affected DPK for the entire look-ahead-window, analyzing and removing their constraints and eventually transforming those DPK starting within the next three weeks into assignable operations, the DOK. On data processing level, the system filters internally for all DPK with a start date within the look-ahead-window and selects them on the $\mathbf{B} e a \mathbf{M}$ !Board. From the selected DPK, whose start lies within the next three weeks, the associated BIM objects are highlighted in the BIM viewer as a visual support for designing operations. The relation between operations and processes is technically represented by IfcProcedure objects being nested in IfcTask objects.

Commitment-planning (Weekly work plan): As transforming operations that CAN be done to operations that WILL be done, a committed-to-be-built-BIM model (CTBB- 
Model) can be generated incorporating the WWP with all committed operations for the next week. By doing so, implicitly an As-built-Forecast-BIM-model will be made available for workers on site as a visual indicator for what needs to be done the next week. During the following control and learning phase, components specified by the CTBB-Model can be checked on site whether they are actually built or not. To this end however, a coordinated BIM model with at least a Level of Development (LOD) 300 is required, in order to ensure a controllable minimum information content.

Control \& Learning: The LPS metrics PPC, Tasks Made Ready (TMR) and Tasks Anticipated (TA) will be supplemented by both the interplay of EVM's metrics PV, EV and AV and Kanban metrics such as average cycle-times (CT) and lead-times (LT) which will be derived from cumulative flow diagrams (CFD). The integration with the BIM model here is exploited by the fact that the CFDs can display the cumulated consumed materials in addition to the pure amount of operations in a given state (eg. made-ready). This in turn represents a further aid, e.g. for the control of material allowance on site. The metrics represent total project measures but can be broken down to different tiers according to Ratajczak et al. (2018) if, e.g., only the performance of a particular trade is of interest. The process status of the single DOKs will be stored in the IfcTask attribute status and serves as a query parameter for the construction progress visualization in the BIM viewer.

\section{DISCUSSION \& CONCLUSION}

This design of the proposed production system aggregated different existing and wellproven techniques: EVM provides methods to determine whether a project is running well or not. LPS offers the instruments to define when and whether value has been earned. Furthermore, it provides a framework for enhanced process stability and workflow reliability which in turn increases the probability of "earning" as much as planned. The missing piece in this puzzle here is BIM, which on the hand provides quantities and information to estimate durations and costs of construction processes. On the other hand, it serves as a better basis for decision-making in phase and look-ahead-planning session as well as a medium for intuitive visualization of the project's status. These features will be unified in the $\mathbf{B} e a \mathbf{M}$ ! production system making use of digital Kanban boards.

Therefore, a model for system integration on data processing level is proposed in this paper, which will be used as a starting point in this ongoing research project to develop software prototypes making BeaM! available for pilot construction projects and thus for evaluation in the sense of the DSR approach. Furthermore, the possible application domain of $\mathbf{B} e a \mathbf{M}$ !, as well as underlying ideals, operational principles and new roles in allusion to Scrum were introduced. In this way it has been shown, that BeaM! represents a production system which fully embodies the Lean philosophy but at the same time functions as a complete project management system harmonizing the target values of quality, schedule and costs with a rigorous adherence to a digital working procedure.

\section{ACKNOWLEDGEMENTS}

This work is part of BIM Simulation Lab-FESR 1086, a research project financed by the European Development Fund (ERDF) Südtirol/Alto Adige. 


\section{REFERENCES}

Ballard, G. (2000a). "The Last Planner system of production control.” Phd Diss., Faculty of Engineering, University of Birmingham.

Ballard, G. (2000b). "Phase Scheduling." Lean Construction Institute: White Paper No. 7, 7, 1-3.

Bhatla, A., and Leite, F. (2012). "Integration Framework of BIM with the Last Planner System." Proc. 20th Ann. Conf. of the Int'l. Group for Lean Construction, International Group for Lean Construction, San Diego, 10.

Borrmann, A., König, M., Koch, C., and Beetz, J. (2018). Building Information Modeling Technology Foundations and Industry Practice. Springer.

Dave, B., Boddy, S., and Koskela, L. (2011). "Visilean: designing a production management system with lean and BIM." 19th Annual Conference of the International Group for Lean Construction, 514-524.

Dave, B., Boddy, S., and Koskela, L. (2013). "Challenges and opportunities in implementing lean and BIM on an infrastructure project." 21st Annual Conference of the International Group for Lean Construction 2013, IGLC 2013, 60-69.

Deshpande, A., Azhar, S., and Amireddy, S. (2014). "A framework for a BIM-based knowledge management system." Procedia Engineering, 113-122.

Fernandes, M. T., and Ribeiro, F. L. (2010). "Exploring agile methods in construction small and medium enterprises: a case study." Journal of Enterprise Information Management, 23(2), 161-180.

Garrido, M. C., Mendes, R., Scheer, S., and Campestrini, T. F. (2015). "Using BIM for last planner system: Case studies in Brazil." Congress on Computing in Civil Engineering, Proceedings, 604-611.

Gerber, D. J., Becerik-Gerber, B., and Kunz, A. (2010). "Building Information Modeling and Lean Construction: Technology, Methodology and Advances From Practice." 18th Ann. Conf. of the Int'l. Group for Lean Construction, 1-11.

Guerriero, A., Kubicki, S., Berroir, F., and Lemaire, C. (2017). "BIM-enhanced collaborative smart technologies for LEAN construction processes.” ICE/ITMC 2017 - Proceedings, 1023-1030.

Hamzeh, F., Ballard, G., and Tommelein, I. D. (2012). "Rethinking Lookahead Planning to Optimize Construction Workflow." Lean Construction Journal, 9(1), 15-34.

Hasan, S., and Akbas, R. (2017). "Managing BIM-Integrated Information for Effective Look-ahead Planning." The 7th Construction Management Conf., Samsun-Turkey.

Highsmith, J. (2002). Agile Software Development Ecosystems. Pearson Education, Bosten.

Khan, S., and Tzortzopoulos, P. (2014). "Effects of the interactions between lps and bim on workflow in two building design projects." 22nd Annual Conference of the International Group for Lean Construction, IGLC 2014, 933-944.

Kim, Y.-W., and Ballard, G. (2010). "Management Thinking in the Earned Value Method System and the Last Planner System." Journal of Management in Engineering, 26(4), 223-228.

Lagos, C., Herrera, R., and Alarcón, L. F. (2017). "Contributions of Information Technologies to Last Planner System implementation.” Proc. LC3, Vol. 1 (CIB 
W78), Heraklion, Greece, II(July), 87-94.

Matt, D. T., and Rauch, E. (2014). "Implementing Lean in Engineer-to-Order Manufacturing." Handbook of Research on Design and Management of Lean Production Systems, V. Modrák and P. Semančo, eds., IGI Global, 148-172.

Mendes Junior, R., Scheer, S., Garrido, M. C., and Campestrini, T. F. (2014). "Utilização da modelagem da informação da construção (BIM) no planejamento e controle da produção: um estudo de caso." XV Encontro Nacional de Tecnologia do Ambiente Construído, 2913-2922.

Modrich, R.-U., and Cousins, B. C. (2017). "Digital kanban boards used in desing and 3D coordination.” Proc. 25th Ann. Conf. of the Int'l. Group for Lean Constr., 663-670.

Mossman, A. (2015). "Last Planner ${ }^{\circledR}: 5+1$ crucial \& collaborative conversations for predictable design \& construction delivery." The Change Business Ltd, 1-16.

Novinsky, M., Nesensohn, C., Ihwas, N., and Haghsheno, S. (2018). "Combined Application of Earned Value Management and Last Planner System in Construction Projects." 26th Ann. Conf. of the Int'l. Group for Lean Construction, 775-785.

Owen, R. L., and Koskela, L. (2006). "An Agile step forward in project management." Proc., 2nd Specialty Conf. on Leadership and Manag. in Construction, 216-224.

Pasetti Monizza, G., Bendetti, C., and Matt, D. T. (2018). "Parametric and Generative Design techniques in mass-production environments as effective enablers of Industry 4.0 approaches in the Building Industry." Automation in Construction, Elsevier, 92 (February), 270-285.

Ratajczak, J., Schimanski, C. P., Marcher, C., Riedl, M., and Matt, D. T. (2018). "Collaborative tool for the construction site to enhance lean project delivery." Cooperative Design, Visualization, and Engineering: 15th International Conference, CDVE 2018, Hangzhou, China, October 21-24, 2018, Proceedings, 192-199.

Sacks, R., Koskela, L., Dave, B. A., and Owen, R. (2010a). "Interaction of Lean and Building Information Modeling in Construction." Journal of Construction Engineering and Management, 136(9), 968-980.

Sacks, R., Radosavljevic, M., and Barak, R. (2010b). "Requirements for building information modeling based lean production management systems for construction." Automation in Construction, Elsevier B.V., 19(5), 641-655.

Sacks, R., Radosavljevic, M., and M. Barak, R. (2010c). "A Building Information Modelling Based Production Control System for Construction." W078-Special Track 18th CIB World Building Congress May 2010 Salford, United Kingdom, 1.

Toledo, M., Olivares, K., and Gónzalez, V. (2016). "Exploration of a Lean - Bim Planning Framework: A Last Planner System and Bim - Based Case Study." Proc. 24th Ann. Conf. of the Int'l. Group for Lean Construction, Boston, 3-12.

Uusitalo, P., Seppänen, O., Peltokorpi, A., and Olivieri, H. (2018). “A Lean Design Management Process Based on Planning the Level of Detail in BIM-Based Design." Proc.35th CIB W78 2018 Conf.: IT in Design, Construction, and Management.

Zhang, L., Li, Y., and Tang, J. (2018). "The Application of the Earned Value Management in the Last Planner System for Project Performance Control." Proceedings of the 17th International Symposium on Advancement of Construction Management and Real Estate, 1-12. 